DOI: $10.1590 /$ permusi20163409

RESENHA

\title{
O Conhecimento profissional na formação do professor de música
}

\author{
Professional Knowledge in Music Teacher Education
}

\author{
Ana Ester Correia Madeira \\ Universidade do Estado de Santa Catarina, Florianópolis, SC, Brasil. \\ ana_ecm6@hotmail.com
}

Resumo: Apresentação do livro Professional Knowledge in Music Teacher Education. Este é o primeiro livro que trata do conhecimento profissional do professor de música. Reúne 13 capítulos organizados em três partes com diferentes finalidades, os quais são escritos por autores de diversos países. Eles apresentam as muitas formas de definir o termo "conhecimento profissional" no ensino de música, sua importância para a formação do educador musical, sua aplicação nas pesquisas realizadas na área e, também, o cruzamento de todas as informações de forma a destacar suas implicações para a prática docente.

Palavras-chave: educação musical; formação docente; conhecimento profissional; teoria e prática.

Abstract: Book review of Professional Knowledge in Music Teacher Education. This is the first book that discusses professional knowledge in music teacher education. The book contains 13 chapters written by authors from different countries, organized into three parts with different purposes. They present the many ways of defining the term "professional knowledge" in music education, its importance for music teaching education, its application in the studies of the area, and also the crosschecking of all information in the book in order to highlight its implications for teaching practice.

Keywords: music education; teacher education; professional knowledge; theory and practice.

Data de recebimento: 013/10/2015

Data de aprovação final: 21/03/2016 


\section{1 - Introdução}

Qual a natureza e a função das diversas formas de conhecimento para o educador musical? Como ele desenvolve o conhecimento profissional? As respostas a estas questões dependem da experiência, cultura ou tradição do sujeito, ao mesmo tempo em que é possível buscar entendê-las, a partir do que outras pessoas, com pontos de vista e ideais diferentes, já experimentaram.

Organizado por Eva Georgi-Hemming ${ }^{1}$, Pamela Burnard ${ }^{2}$ e Sven-Erik Holgersen ${ }^{3}$, o livro Professional Knowledge in Music Teacher Education é o primeiro na área da educação musical a tratar do conhecimento profissional do educador musical reunindo, com a introdução, 13 capítulos escritos por diferentes autores de diversos países. Através desta obra, eles apresentam as muitas formas de definir o termo "conhecimento profissional" e a sua importância para a prática e a formação do professor de música.

O livro está dividido em três partes. Na primeira após a introdução, com cinco capítulos, são apresentados artigos sobre a natureza do conhecimento, mostrando a importância de diversas concepções e perspectivas teóricas a respeito. A segunda parte, também composta por cinco capítulos, trata do processo de construção e desenvolvimento do conhecimento profissional, destacando as questões culturais nessa transformação, contribuindo para demonstrar como não só a teoria pode auxiliar o educador musical no exercício de sua profissão. A terceira parte contém dois capítulos voltados à apresentação, análise e compreensão das implicações e desafios das práticas pedagógicas contemporâneas, sendo que um realiza um cruzamento com as ideias apresentadas nos capítulos anteriores e o outro apresenta a conclusão da obra.

\footnotetext{
${ }^{1}$ Professora e coordenadora do Departamento de Música, Teatro e Artes da Universidade de Örebro (Suécia). Ministra disciplinas de educação musical, filosofia e sociologia da música.

2 Pesquisadora da área da educação musical na Universidade de Cambridge (Reino Unido), onde ministra disciplinas de Artes, Criatividade, Educação e Cultura, e Pesquisa em Educação.

3 Professor associado ao curso de Educação Musical na Universidade Aarhus (Dinamarca), onde é coordenador do Mestrado em Educação e ministra disciplinas de educação musical e metodologia da pesquisa.
} 
Para introduzir a obra, Burnard apresenta o tema central do livro e importantes definições que serão trabalhadas no decorrer dos capítulos (conhecimento profissional, formação inicial, prática docente e desenvolvimento profissional), destacando uma questão que perpassa por toda a obra: qual tipo de conhecimento profissional é valorizado por professores que formam educadores musicais? Isso evidencia a necessidade de repensar o papel da prática docente na criação, aplicação e disseminação do conhecimento profissional do educador musical em formação.

\section{2 - Primeira parte: a natureza do conhecimento profissional}

No capítulo 1, Georgii-Hemming destaca que o conhecimento em educação musical está em voga, mas não é problematizado. É trabalhado a partir de uma visão hermenêutica que sustenta uma relação entre o conhecimento familiar e não familiar do professor, sendo que o processo para a sua construção é marcado pela união da experiência com os fatos, e o que ele conhece e compreende como certo, ou imagina que assim o seja. Este processo traz contribuições às discussões sobre música em geral, com destaque para o ensino de música e a formação de professores nesta área.

O norueguês Varkøy, no capítulo 2, identifica a tendência de defender a música na escola somente pela sua utilidade para a educação em geral. Buscando ir além, o autor parte de filósofos como Aristóteles, Immanuel Kant, Martin Heidegger e Hannah Arendt, entendendo que são fundamentais para o desenvolvimento de uma filosofia crítica e orientada sobre música, focando a formação de professores nesta área. 0 objetivo deste processo é contribuir para o desenvolvimento das reflexões destes profissionais.

No capítulo 3, Holgersen e Holst, através de um estudo fenomenológico realizado na Dinamarca, discutem sobre o profissionalismo na formação do educador musical, apresentando uma compreensão a respeito da prática e do conhecimento. Baseados 
em Dietrich Benner, afirmam que existem três áreas - a cotidiana, a profissional e a científica - que perpassam a prática e o conhecimento. Todas se dispõem num processo contínuo no profissionalismo do educador. Desde o conceito de conhecimento e profissionalismo (experiência e prática cotidiana, conhecimento e prática profissional, conhecimento e prática cientifica), até o conceito de didática, os autores entendem a importância da relação entre teoria e prática na formação do educador musical, destacando a necessidade de conhecer e entender as perspectivas teóricas da profissão.

Stephens, professor da Universidade de Aberdeen na Escócia, no capítulo 4, considera formas alternativas de conhecimento apropriadas aos músicos e educadores musicais, tais como imaginação e histórias de vida que oferecem caminhos para o saber tanto individuais quanto coletivos que podem ser significativos. Nessa perspectiva, o autor apresenta o conceito de conhecimento prático para o músico e o educador musical, a importância da educação para a vida, a relação entre crença, verdade e conhecimento, bem como a diferença entre realidades subjetivas e objetivas. Ele entende que é preciso levar os estudantes para além do que é óbvio, afirmando, com base em Francis Bacon, que todo conhecimento é poder, sendo alguns mais poderosos que outros.

Burnard tem como objetivo, no capítulo 5, identificar e problematizar os saberes dos professores de música partindo de três perguntas: (1) por que ampliar as concepções sobre o conhecimento musical?; (2) quais tipos de conhecimento musical são aperfeiçoados e por que são importantes no contexto de ensino de cada professor?; e (3) o que é conhecimento profissional para o professor de música? A autora aponta para a criatividade na formação do educador musical, entendendo que isso gera oportunidades para explorar e formar valores, além de desenvolver habilidades sociais, através da utilização criativa dos variados espaços de aplicação do conhecimento. Portanto, os educadores musicais precisam ser produtores, e não apenas usuários, do conhecimento.

Nessa primeira parte, notou-se que a profissão do professor de música é construída na união da teoria com a prática, ou seja, do que está nos livros com a experiência; a 
aplicação daquilo que, até então, era teórico. Esse processo acontece de forma contínua a partir da reflexão na e sobre a prática, o que Schön (2000) denomina de "conhecerna-ação", referindo-se aos tipos de conhecimentos revelados nas ações humanas, públicas ou privadas, pois não são soluções técnicas que resolvem problemas práticos. Quando os autores colocam que é necessário que a formação docente caminhe para além do óbvio, pode-se inferir que valorizam a análise e a reflexão como partes integrantes da prática do educador musical, levando-o à mudança quando esta for julgada necessária.

Essa é a descrição do professor como um pesquisador, alguém que conhece, reflete e analisa a si mesmo como profissional e a sua prática, entendendo que o papel básico da reflexão é "olhar para dentro", conforme afirma Larrosa (1994). Sendo assim, ele pode contribuir significativamente para a sua própria prática, sendo produtor e não apenas consumidor do conhecimento que, nesse caso, pode ser a própria experiência (ROBERTS, 1994; ZEICHNER, 1998; NÓVOA, 2002).

\section{3 - Segunda parte: a construção do conhecimento profissional}

No capítulo 6, Burton defende que a experiência direta com o ensino nos anos iniciais da formação do educador musical é um solo fértil que o torna efetivo. Fundamentada na perspectiva construtivista de John Dewey, a autora entende que a prática profissional é formada por professores que têm profundo conhecimento (a) dos seus alunos e dos contextos sociais em que estão inseridos; (b) do currículo e da disciplina que leciona; e (c) do ensino. A autora coloca em prática tais premissas, realizando uma pesquisa no estágio em educação musical de uma universidade nos Estados Unidos. Os resultados indicaram a necessidade dos participantes do estudo em gerir o tempo e o conteúdo, além de saber mostrar e demonstrar os exemplos musicais aplicando uma abordagem mais interativa. Ao mesmo tempo, foi observado um parâmetro de satisfação a partir do momento em que eles encontraram no estágio uma plataforma 
que proporciona vantagens à formação inicial do educador musical, tornando-se uma opção de carreira viável.

O capítulo 7 é marcado pelas reflexões de Lehmann-Wermser a respeito dos fenômenos que influenciam a carreira do músico e do professor de música na Alemanha. Os princípios que levam as pessoas a estudar música no ensino superior estão na estrutura curricular do curso e na necessidade de desenvolvimento pessoal, afirma. No entanto, apesar de fazerem tal escolha por serem músicos, eles não aprendem, efetivamente, como ensinar música. É necessário, portanto, discutir o contexto da profissão, pois não significa, apenas, adquirir um grau para o mercado de trabalho. 0 autor observou também que, na formação do educador musical no país, o desafio é estruturar programas de graduação pensando em duas finalidades: a formação instrumental, visando ao desenvolvimento e experiências pessoais; e o desenvolvimento das competências que permitam ao profissional trabalhar com os materiais disponíveis nas aulas de música em escolas regulares.

No capítulo 8, Fink-Jensen buscou compreender como a teoria contribui para o desenvolvimento da prática docente. Tomando como foco o professor de música como pesquisador, sua intenção foi identificar como a relação entre teoria e prática acontece na formação desse profissional. Propôs, portanto, a aplicação de uma estratégia de ensino para a formação docente denominada de "práticas surpreendentes", ou seja, princípios gerais para um procedimento que é aplicado numa disciplina e será seguido pelos estudantes. 0 termo "surpreendente", advindo da antropologia cultural, se refere a um sentimento universal que se manifesta de forma diferente de acordo com o contexto onde é evidenciado. Neste caso, a resposta resultante dessa manifestação é entendida como um fenômeno que pode surgir no encontro com algo ou alguém numa situação específica que culmina numa ruptura com expectativas desenvolvidas a partir de hábitos, experiências e conhecimentos anteriores. Dois exemplos da aplicação dessa estratégia são apresentados num contexto de formação superior na Dinamarca, descrevendo e discutindo como o nível de familiaridade do estudante com o campo influencia na prática docente. 
Mateiro e Westvall defendem, no capítulo 9, que o conhecimento profissional dos professores de música é influenciado pelo contexto cultural e social onde ele é exposto, internalizado e aplicado. Foi observada a percepção de um grupo de licenciandos em música na Suécia, quando expostos a atividades familiares (uma aula de música na escola gravada em vídeo) num contexto educacional diferente (Canadá). Os estudantes em formação docente identificaram como aspectos atraentes, a forma como o professor estruturou e realizou a aula; a relação aluno-professor; e a escolha do professor referente ao conteúdo a ser ensinado. Diante disso, eles destacaram três momentos da aula: dois estavam ligados ao seu contexto e um não lhes era familiar. Os dois primeiros momentos foram marcados pela igualdade e inclusão, nos quais os estudantes de música acentuaram os princípios democráticos da educação. 0 terceiro momento foi marcado pela não familiaridade, relacionado à dinâmica da aula em si, pois a maneira como o professor conduziu a aula no Canadá difere da Suécia. As autoras destacaram, portanto, a importância de balancear o conhecimento familiar com o não familiar, sugerindo que opiniões fixas não precisam, necessariamente, permanecer.

Perkins e Triantafyllaki, autoras do capítulo 10, analisam o "saber-como" dos professores, o qual consiste em ter conhecimento sobre como conduzir os vários processos que contribuem para a atuação profissional, focando em como e por que é ensinado; e como eles o relacionam com a própria história de vida, as circunstâncias e as culturas nos seus locais de trabalho. A intenção foi esclarecer as diferentes formas em que o "saber-como" é socialmente construído e o papel do habitus profissional conceito de Pierre Bourdieu - que é importante nesse processo. A partir de uma pesquisa realizada no Reino Unido, as autoras procuram definir o conceito de "habitus profissional" para um professor de música no conservatório e um na escola regular. As implicações deste estudo para a formação do educador musical estão em reconhecer a inconstância que há em ser professor; compreender como ser a pessoa correta para o trabalho; e como relacionar planejamento e prática no local de trabalho.

A segunda parte da obra apresentou pesquisas empíricas a respeito da formação docente do professor de música, indicando que as questões alusivas à sala de aula preocupam os estudantes em processo formativo, pois o que é novo pode, 
naturalmente, gerar o estranhamento, conforme Fink-Jensen (2013) no capítulo 8. Nesse caso, estruturar currículos de graduação ou estratégias de ensino para disciplinas práticas de formação docente torna-se um desafio constante na construção dos cursos de educação musical.

Em todo o caso, não apenas a construção de programas de graduação bem estruturados deve ser considerada, mas também o fato de que a experiência, sobretudo a familiaridade com o contexto de atuação também influencia na adaptação do professor de música à realidade da sala de aula. Como já colocaram Perkins e Triantafyllaki (2013) no capítulo 10, é preciso reconhecer a inconstância que há em ser professor, algo que não depende somente do currículo, mas também da prática em si.

\section{4 - Terceira parte: os desafios contemporâneos das práticas pedagógico-musicais}

O capítulo 11, escrito por Holgersen e Burnard, apresenta o cruzamento de todas as perspectivas teóricas apresentadas nos capítulos anteriores, destacando o papel dos diferentes tipos de conhecimento que fundamentam o desenvolvimento ( $\mathrm{e}$ melhoramento) contínuo do ensino e dos professores de música. 0 capítulo está dividido em quatro partes: (1) os diferentes tipos de profissionalismo; (2) o desenvolvimento do conhecimento profissional; (3) o espaço do conhecimento na educação musical; e (4) um modelo de reflexão didática. Os autores defendem a união da prática profissional com a pesquisa, incluindo a colaboração e reflexão do professor de música, a investigação de sua prática, a realização de parcerias criativas e culturais e, por fim, a exploração de novas tecnologias.

De maneira conclusiva, Georgii-Hemming destaca, no capítulo 12, a existência de uma busca constante por tornar a educação musical uma profissão cada vez mais consolidada, considerando os desafios contemporâneos das práticas pedagógicomusicais. A sua argumentação é dividida em três sessões, fundamentando-se nas dimensões filosóficas do conhecimento pedagógico: (1) a educação musical como 
profissão; (2) a profissionalização do trabalho; e (3) o conhecimento profissional com uma abordagem de ensino crítica e reflexiva. Portanto, a formação de professores de música deve ter como foco a educação profissional dos educadores musicais, de forma a estabilizar e tornar oficial tal profissão.

\section{5 - Considerações finais}

Inicialmente, o livro apresenta perspectivas teóricas para explicar o conhecimento profissional do educador musical. Os capítulos seguintes estão fundamentados na prática do educador musical, ou seja, em pesquisas empíricas para, então, na terceira parte, ser exposta uma discussão sobre todas as premissas teóricas mostradas no decorrer do livro. A forma como a obra foi organizada fornece ao leitor diferentes perspectivas sobre o conhecimento profissional do professor de música, aplicado a contextos culturais diferentes. Também são apresentadas referências importantes que oferecem uma ampla compreensão sobre a formação docente em música, tanto para conservatórios, como para escolas regulares e instituições de ensino superior.

Outro aspecto da obra é a presença de trabalhos teórico-práticos. No livro, alguns capítulos se pautam mais na parte empírica da pesquisa apresentada (capítulos 3, 6, 8 e 9), porém não deixam de desenvolver, com qualidade, a perspectiva teórica em que apoia cada investigação. Os demais capítulos (capítulos 1, 2, 4, 5, 7, 10,11 e 12), embora ligados a uma realidade cultural, são modelados à reflexão teórica de conceitos, relacionando tais questões à formação docente do educador musical.

Nos capítulos 3, 4 e 7, nota-se a presença de uma discussão sobre a formação do músico e educador musical, como eles entendem o conhecimento profissional e de que forma atuam como instrumentistas e educadores musicais ao mesmo tempo, no caso de conservatórios, por exemplo. Observa-se que esta não é uma reflexão nova, mas que não se esgotou, pois o equilíbrio entre a formação do músico e do educador musical, ainda é um dilema nos cursos de música, desenvolvendo competências nessas duas 
MADEIRA, Ana Ester Correia. (2016) 0 conhecimento profissional na formação do educador musical. Per Musi. Ed. por Fausto Borém, Eduardo Rosse e Débora Borburema. Belo Horizonte: UFMG, n.34, p.211-223.

realidades, como é o caso das universidades brasileiras que formam esses profissionais.

Sendo assim, o livro se configura como um importante material para a formação docente na área de educação musical. São capítulos densos em conteúdo teórico e empírico que subsidiam as discussões entre os profissionais do ensino de música, através da fusão entre teoria e prática. Recomenda-se essa obra como leitura essencial a todo e qualquer estudante em formação docente, especialmente aos que fazem parte da área de música. Ela auxilia a entender com mais profundidade o conhecimento profissional do educador musical e sua aplicabilidade para a atuação profissional não só na escola básica, mas também no conservatório, na universidade ou em qualquer outro espaço que se configure como campo de trabalho para o professor de música.

\section{Referências}

1. BURNARD, Pamela. Problematizing what counts as knowledge and the production of Knowledge in music. (2013). In: GEORGI-HEMMING, Eva; BURNARD, Pamela; HOLGERSEN, Sven-Erik. Professional knowledge in music teacher education. Hampshire, England: Ashgate, p. 97-108.

2. BURNARD, Pamela. The context for professional knowledge in music teacher education. (2013). In: GEORGI-HEMMING, Eva; BURNARD, Pamela; HOLGERSEN, Sven-Erik. Professional knowledge in music teacher education. Hampshire, England: Ashgate, p. 1-15.

3. BURTON, Suzanne L. Constructing professional paths in a school-embedded methods course. (2013). In: GEORGI-HEMMING, Eva; BURNARD, Pamela; HOLGERSEN, Sven-Erik. Professional knowledge in music teacher education. Hampshire, England: Ashgate, p. 111-125.

4. FINK-JENSEN, Kirsten. Astonishing practices: a teaching strategy in music teacher education. (2013). In: GEORGI-HEMMING, Eva; BURNARD, Pamela; HOLGERSEN, 
Sven-Erik. Professional knowledge in music teacher education. Hampshire, England: Ashgate, p. 139-155.

5. GEORGI-HEMMING, Eva; BURNARD, Pamela; HOLGERSEN, Sven-Erik. (2013). Professional knowledge in music teacher education. Hampshire, England: Ashgate.

6. GEORGII-HEMMING, Eva. Meeting the challenges of music teacher education. (2013). In: GEORGI-HEMMING, Eva; BURNARD, Pamela; HOLGERSEN, Sven-Erik. Professional knowledge in music teacher education. Hampshire, England: Ashgate, p. 203-213.

7. GEORGII-HEMMING, Eva. Music as knowledge in an educational context. (2013). In: GEORGI-HEMMING, Eva; BURNARD, Pamela; HOLGERSEN, Sven-Erik. Professional knowledge in music teacher education. Hampshire, England: Ashgate, p. 19-37.

8. HOLGERSEN, Sven-Erik; BURNARD, Pamela. Different types of knowledges forming professionalism: a vision of post-millennial music teacher education. (2013). In: GEORGI-HEMMING, Eva; BURNARD, Pamela; HOLGERSEN, Sven-Erik. Professional knowledge in music teacher education. Hampshire, England: Ashgate, p. 189-201.

9. HOLGERSEN, Sven-Erik; HOLST, Finn. Knowledge and professionalism in music teacher education. (2013). In: GEORGI-HEMMING, Eva; BURNARD, Pamela; HOLGERSEN, Sven-Erik. Professional knowledge in music teacher education. Hampshire, England: Ashgate, p. 51-71.

10. LARROSA, Jorge. (1994). Tecnologias do eu e educação. In: SILVA, Tomaz Tadeu da (Org.). 0 sujeito da educação: estudos foucaultianos. Petrópolis, RJ: Vozes, p. 35-86.

11. LEHMANN-WERMSER, Andreas. Artistic knowledge among music education students in Germany: being trained to be exactly what? (2013). In: GEORGI- 
MADEIRA, Ana Ester Correia. (2016) 0 conhecimento profissional na formação do educador musical. Per Musi. Ed. por Fausto Borém, Eduardo Rosse e Débora Borburema. Belo Horizonte: UFMG, n.34, p.211-223.

HEMMING, Eva; BURNARD, Pamela; HOLGERSEN, Sven-Erik. Professional

knowledge in music teacher education. Hampshire, England: Ashgate, p. 127-138.

12. MATEIRO, Teresa; WESTVALL, Maria. The cultural dimensions of music teachers' professional knowledge. (2013). In: GEORGI-HEMMING, Eva; BURNARD, Pamela; HOLGERSEN, Sven-Erik. Professional knowledge in music teacher education. Hampshire, England: Ashgate, p. 157-172.

13. NÓVOA, António. (2002). Formação de professores e trabalho pedagógico. Lisboa: Educa.

14. PERKINS, Rosie; TRIANTAFYLLAKI, Angeliki. School and conservatoire music teachers' 'vocational habitus': lessons for music teacher education. (2013). In: GEORGI-HEMMING, Eva; BURNARD, Pamela; HOLGERSEN, Sven-Erik. Professional knowledge in music teacher education. Hampshire, England: Ashgate, p. 173-185.

15. ROBERTS, Brian. (1994). Music teachers as researchers. International Journal of Music Education, v. 1, n.23, p. 24-33.

16. SCHÖN, Donald A. (2000). Educando o profissional reflexivo: um novo design para o ensino e a aprendizagem. Porto Alegre: Artmed.

17. STEPHENS, Jonathan. Artistic Knowledge in Practice. (2013). In: GEORGIHEMMING, Eva; BURNARD, Pamela; HOLGERSEN, Sven-Erik. Professional knowledge in music teacher education. Hampshire, England: Ashgate, p. 73-96.

18. VARKØY, Øivind. Technical rationality, techne and music education. (2013). In: GEORGI-HEMMING, Eva; BURNARD, Pamela; HOLGERSEN, Sven-Erik. Professional knowledge in music teacher education. Hampshire, England: Ashgate, p. 39-50. 
19. ZEICHNER, Kenneth. (1998). Para além da divisão entre professor-pesquisador e pesquisador acadêmico. In: GERALDI, Corinta Maria Grisolia; FIORENTINI, Dario; PEREIRA, Elisabete Monteiro de A. (Orgs.). Cartografias do trabalho docente: professor(a)-pesquisador(a). Campinas, SP: Mercado de Letras - Associação de Leitura do Brasil, p. 207-236.

Nota sobre a autora

Ana Ester Correia Madeira é graduada em Música-Licenciatura pela Universidade do Estado de Santa Catarina (2012) e Mestre em Música (2015) pelo Programa de Pós-Graduação em Música (PPGMUS) da mesma universidade, integrando o Grupo de Pesquisa "Educação Musical e Formação Docente", coordenado pela professora Dra. Teresa Mateiro, na instituição. É professora de música no Colégio Jardim Anchieta e em dois projetos sociais (Projeto CRER e Instituto Mais que Vencedores), atuando na Educação Infantil e nos Anos Iniciais do Ensino Fundamental. É cantora e integrante do Grupo de Evangelização Infantil Semeando a Esperança e trabalha com música e teatro de fantoches. É professora de dança e piano na Igreja Evangélica Assembleia de Deus (Florianópolis/SC), além de pianista e corista (soprano) do Coro Vozes de Sião no mesmo local. Pesquisa, principalmente, os seguintes temas: canto, música na igreja, educação musical e formação docente, motivação, escola pública e ensino fundamental. 